VII Congresso Brasileiro de Informática na Educação (CBIE 2018)

Anais do XXIV Workshop de Informática na Escola (WIE 2018)

\title{
Um Relato de Experiência Usando Google Sala de Aula para Apoio à Aprendizagem de Química
}

\author{
Gerla Myrcea Lima da Silva ${ }^{1}$, José Francisco de Magalhães Netto ${ }^{2}$ \\ ${ }^{1}$ Secretaria de Estado de Educação e Qualidade do Ensino - SEDUC - AM - Brasil \\ ${ }^{2}$ Programa de Pós-Graduação em Ensino de Ciências e Matemática - PPGCIEM - \\ Universidade Federal do Amazonas - Manaus - AM - Brasil \\ gerlamyrcea@gmail.com, jnetto@icomp.ufam.edu.br
}

\begin{abstract}
It is growing among educational researchers and teachers the concern with the methodological conceptions adopted in the Brazilian schools with the expansion of the use of the Internet. We used the Google Classroom with the purpose of inserting it as an auxiliary tool in the teaching and learning of Chemistry, inside and outside the context of the classroom. The research was carried out in a puclic school in Manaus, in a class of $3 r d y e a r$ of High School. The data obtained through a questionnaire were treated following the Content Analysis technique. The insertion of the platform showed itself as effective in the evaluation of the Hydrocarbons content, being considered didactic and effective in the communication.
\end{abstract}

Resumo. É crescente entre pesquisadores na área de Educação e professores a preocupação com as concepções metodológicas adotadas nas escolas brasileiras com a ampliação do uso da Internet. Utilizou-se o Google Sala de Aula com o objetivo de inseri-lo como ferramenta auxiliar no ensino e aprendizagem da Química dentro e fora do contexto de sala de aula. Realizouse a pesquisa numa escola da rede pública de Manaus, numa turma de 3 o ano do Ensino Médio. Os dados obtidos por meio de questionário foram tratados seguindo a técnica de Análise de Conteúdo. A inserção da plataforma mostrou-se efetiva na avaliação do conteúdo Hidrocarbonetos, sendo considerada didática e efetiva na comunicação.

\section{Introdução}

É crescente entre pesquisadores na área de Educação e professores a preocupação com as concepções metodológicas adotadas nas escolas brasileiras. Mesmo com todos os indicativos de que vivemos na era tecnológica e que os acessos às informações e comunicação podem ser explorados de formas diversas na ampliação do conhecimento, estas ferramentas pouco têm sido adotadas para fins de ensino e aprendizagem nas escolas das redes públicas do Brasil.

A inserção das ferramentas tecnológicas tornou-se uma tendência como abordagem metodológica indispensável na busca por qualidade no ensino, considerando que os tempos mudaram, o público tornou-se mais exigente e os meios de comunicação 
VII Congresso Brasileiro de Informática na Educação (CBIE 2018)

Anais do XXIV Workshop de Informática na Escola (WIE 2018)

se ampliaram com o uso da Internet. Seguir os avanços da ciência e tecnologia tornou-se uma necessidade e não uma opção.

Neste contexto, o espaço educacional tem o poder de influenciar as mudanças sociais, logo, torna-se uma ponte favorável na construção do conhecimento, viabilizando caminhos que evidencie sentidos e ative as motivações do sujeito em desenvolvimento intelectual, atendendo aos anseios do mundo globalizado [Leite, 2017].

O uso das tecnologias como apoio ao ensino presencial colabora para a redução das dificuldades do processo ao passo que os alunos dedicam mais tempo ao conteúdo em estudo [Puerta et al, 2008], sobretudo, conferindo-lhes condições para melhor se posicionarem frente às mudanças contínuas que os cercam [Brasil, 2013].

Neste sentido, o objetivo deste artigo é inserir a plataforma Google Sala de Aula como ferramenta auxiliar no ensino e aprendizagem da Química dentro e fora do contexto de sala de aula.

O Google Sala de Aula, também conhecido por Google Classroom, é a plataforma educacional do Google, criado em 2014. Com a ferramenta o professor pode gerenciar conteúdo, simplificar a criação, distribuição e avaliação de trabalhos escolares, bem como características de interatividade e colaboração entre os agentes do processo de aprendizagem. Tais funcionalidades em conjunto com outras existentes na plataforma facilitam a troca de conhecimentos entre os agentes do processo por meio dos caminhos alternativos de comunicação entre eles.

Uma das características mais significativas no Google Sala de Aula está na ampliação do espaço-tempo, o que torna o processo de aprendizagem contínuo e dinâmico. Dessa forma, a possibilidade de interação e comunicação entre professor e aluno a qualquer hora e em qualquer lugar, além de criar vínculos de afetividade e confiança, amplia o processo de ensino e aprendizagem para além do contexto da sala de aula. Desse modo, acredita-se que o uso da plataforma Google Sala de Aula será de fácil aceitação e bem utilizada por professores e estudantes conectados no mundo informatizado, a julgar por seu fácil acesso e características colaborativas.

Considerando o avanço acelerado das tecnologias no contexto atual é imprescindível ajustar o aprendizado profissional dos professores às habilidades que buscamos desenvolver nos nossos alunos para que juntos acompanhem as mudanças contínuas que acontecem no século XXI [Wiit, 2015]. Contudo, os profissionais da educação precisam ser envolvidos nos processos de aprendizagem, seguindo orientações e etapas de desenvolvimento que os conduzam ao aprendizado efetivo ou insira-os em ambientes colaborativos eficazes. Para tanto, é preciso uma ação pedagógica que incentive o uso das tecnologias nas atividades escolares, estendendo-se para o contexto de sala de aula [Hawley e Valli, 2000 apud Wiit, 2015].

Assim, este trabalho descreve a introdução do Google Sala de Aula como ferramenta de avaliação online numa turma do $3^{\circ}$ ano do Ensino Médio, matutino, de uma escola pública da Zona Leste de Manaus, na disciplina de Química Orgânica. Pretende-se com o uso da ferramenta online criar um meio de comunicação efetivo entre 
VII Congresso Brasileiro de Informática na Educação (CBIE 2018)

Anais do XXIV Workshop de Informática na Escola (WIE 2018)

professor e aluno (mediador e sujeito da aprendizagem), considerando que o espaço físico não é suficiente para o direcionamento e acompanhamento da aprendizagem dos alunos.

Para atender o objetivo proposto, estruturou-se este em 5 seções: Na seção 2, são descritos os trabalhos correlatos. $\mathrm{Na}$ seção 3, apresentamos o desenvolvimento metodológico da pesquisa. Na seção 4, descrevemos os resultados. E, por fim, a seção 5 apresenta as considerações finais sobre o estudo e trabalhos futuros.

\section{Trabalhos Correlatos}

Muitos são os trabalhos com enfoque em metodologias e ferramentas que contemplam o uso da informática na Educação. Percebe-se que a adesão pelos aparatos tecnológicos tem conquistado os mais diferentes níveis de escolaridade e um público com características diferenciadas. Os trabalhos a seguir, corroboram para esta pesquisa, neste segmento.

Schiehl \& Gasparini [2016] mostram as contribuições da plataforma Google Sala de Aula para o Ensino Híbrido. Dentre as modalidades deste ensino, os autores fazem uso do modelo de rotação por estações, com atividades em diferentes graus de dificuldades, contudo com possibilidade de interação e ajuda mútua dos grupos entre si. O uso do modelo de Rotação por Estações por meio das ferramentas do Google Sala de Aula aproximou professor e alunos, promovendo colaboração entre os estudantes.

Schiehl \& Gasparini [2017] ao aprofundar os estudos sobre o Ensino Híbrido por meio de um Mapeamento Sistemático da Literatura (MSL), encontraram resultados satisfatórios para o ensino e aprendizagem da Matemática envolvendo sala de aula e o uso de tecnologias com interação on-line. Os dados apontam que o uso dessa combinação tem sido expressivo apenas nas universidades $(85 \%)$ e incipiente nas redes municipais e estaduais de ensino (6\% e 3\%, respectivamente), sendo o Ambiente Virtual de Aprendizagem (AVA) a ferramenta mais utilizada nessa combinação (56\%), seguido do Google (17\%) e Facebook (7\%).

Souza [2016] ao acompanhar por duas semanas o acesso feito pelos alunos na plataforma Google Sala de Aula, identificou como único ponto negativo da ferramenta, a limitação que alguns alunos tiveram no acesso à Internet, mas que no geral, a maioria dos alunos se envolveu mais efetivamente com a disciplina de Matemática, por considerar que a ferramenta facilitou o diálogo com os colegas da turma e a troca de experiências por estes fora do contexto de sala de aula.

No uso do Simulador PhET, Silva et al. [2016] mostraram resultados animadores no Ensino da Química. Os autores descrevem a evolução conceitual e o envolvimento dos mesmos na disciplina. Os dados apontam que a atividade intensificou a relação entre os agentes do processo de aprendizagem, com mudança de comportamento e atitudes de parte dos alunos que demonstravam desinteresse e/ou dificuldade de assimilação do conteúdo, quando o conteúdo era trabalhado de forma abstrata e em nível microscópico. 
VII Congresso Brasileiro de Informática na Educação (CBIE 2018)

Anais do XXIV Workshop de Informática na Escola (WIE 2018)

Resultados semelhantes foram encontrados por Araújo [2016] ao trabalhar com o Google Sala de Aula na aplicação de atividades referentes à Matemática. O autor descreveu as motivações, o envolvimento, bem como o interesse dos alunos pelo conteúdo. De modo geral, houve comprometimento da turma estudada e uma minoria se manteve alheia as atividades, realizando-as apenas para obtenção de nota na disciplina.

Analisando os estudos aqui mencionados, os quais descrevem situações com o uso/inserção das ferramentas tecnológicas no contexto escolar, optou-se neste trabalho pela plataforma Google Sala de Aula, cujas características de interação e o formato de organização das ferramentas contribuem na otimização do tempo, sobretudo, conduzindo de forma didática o caminho a ser desenvolvido pelos alunos na realização das atividades.

\section{Desenvolvimento Metodológico}

Nesta seção descrevemos o percurso metodológico adotado nesta pesquisa.

\subsection{Contexto e desenvolvimento da pesquisa}

O presente estudo foi realizado numa escola da Rede Pública do Estado do Amazonas, Zona Leste de Manaus. A investigação na sala de aula aconteceu numa turma de $3^{\circ}$ ano do Ensino médio com 39 alunos matriculados, matutino, faixa etária média de 17 anos. O conteúdo avaliado foi "A origem do petróleo", explorando a função orgânica Hidrocarbonetos (moléculas constituídas por átomos de carbono e hidrogênio). A coleta inicial dos dados aconteceu na segunda quinzena do mês de maio de 2018. A plataforma Google Sala de Aula foi apresentada para os alunos usando data show por meio de um tutorial criado pelo professor. A pesquisa é qualitativa por considerar a ação das pessoas que atribuem sentido próprio a ser revelado [Alves-Mazotti,1998]. Como coleta de dados optou-se pela observação e questionário com pergunta aberta e múltipla escolha. Os dados da pesquisa foram tratados segundo o instrumento de Análise de Conteúdo, proposto por Bardin [2011], favorecendo a organização dos dados obtidos e o surgimento das categorias de análise. Como avaliação, foram anexados três vídeos de apoio e um questionário de avaliação do conteúdo. Os vídeos foram baixados do Youtube. São eles: Aula de Petróleo ${ }^{1}$, A Origem do Petróleo ${ }^{2}$ e Química do Petróleo ${ }^{3}$.

\subsection{O Google Sala de Aula}

Para usar o Google Sala de Aula é necessário fazer login no computador ou dispositivo móvel (Android, iPhone e iPad) e posteriormente, participar da turma. A participação na turma é possível por dois meios: a) Código da turma: fornecido pelo professor; b) Convite feito pelo professor: enviado o convite pelo professor, aparecerá a opção Participar da turma na página inicial do Google Sala de Aula. As figuras a seguir mostram as sequências a serem seguidas via computador. Inicialmente o aluno deverá acessar classroom.google.com, depois devem seguir as marcações de vermelho nas figuras a seguir. Assim, o aluno terá acesso às postagens feitas pelo professor.

Disponível em: ${ }^{1}$ https://www.youtube.com/watch?v=XbilFREZ65k, acessado em 08/05/2018;

${ }^{2}$ https://www.youtube.com/watch?v=yhzvnpK7hPs\&t=35s; acessado em 08/05/2018;

${ }^{3}$ https://www.youtube.com/watch?v=YquU85f7aW4, acessado em 08/05/2018. 
VII Congresso Brasileiro de Informática na Educação (CBIE 2018)

Anais do XXIV Workshop de Informática na Escola (WIE 2018)

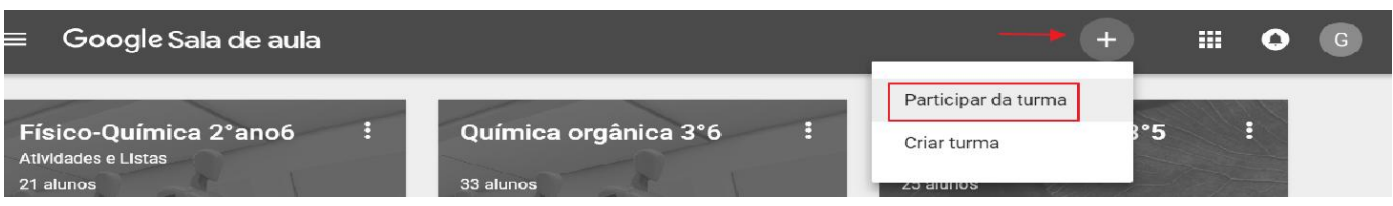

Figura 1: Participar com o código da turma. Fonte: Plataforma de acesso do professor.

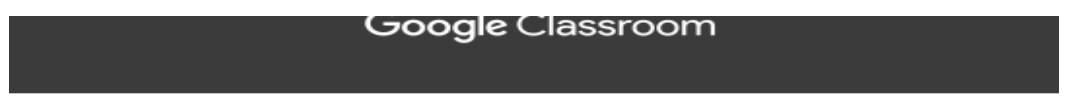

Olá,

Gerly Lima (gerlamyrcea@gmail.com) convidou você para a turma Química Orgânica $\underline{3^{\circ} 4}$ (Matutino) $2^{\circ}$ Bimestre_AV1.

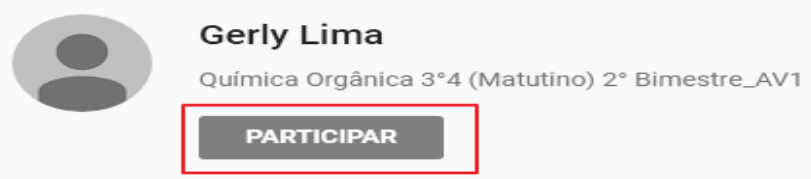

Figura 2: Participar por meio de convite.

Fonte: Plataforma de acesso do professor.

Dentre as ferramentas disponíveis no Google Sala de Aula, foram utilizados nesta pesquisa: Aviso, tarefas, perguntas e reutilização de postagem, anexos de vídeos do Youtube, mensagens e notificações por e-mail. Criou-se uma turma intitulada "Química Orgânica $3^{\circ}$ ano 4" e a participação dos alunos nesta, aconteceu por meio do código da turma ou usando a conta de e-mail (após aceite do convite do professor).

\section{Resultados e Discussões}

A seção a seguir é destinada à análise dos dados apresentados na pesquisa.

\section{a) Questionário avaliativo sobre o conteúdo - Hidrocarbonetos}

Em conversa com os alunos, os mesmos disseram ter encontrado alguma dificuldade na realização da atividade como, por exemplo, em saber se as respostas poderiam ser colocadas numa única postagem e se tinham enviado ao professor corretamente. Tal insegurança é normal, visto que eles não tinham tido contato com a plataforma anteriormente. Contudo, eles foram proativos e buscaram outros mecanismos para solucionar as dúvidas que surgiam.

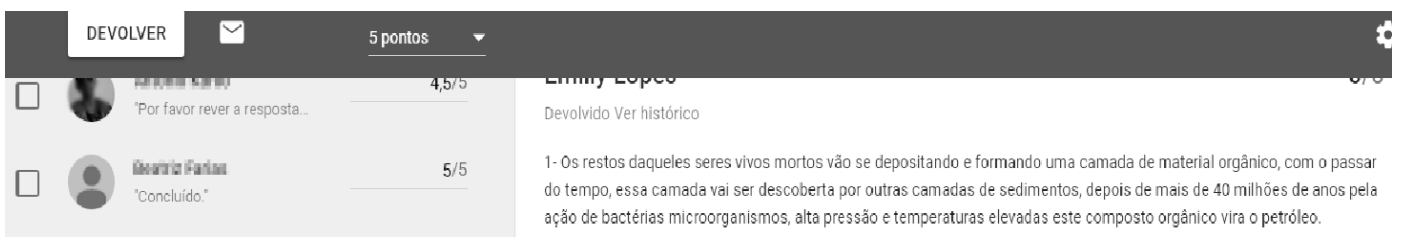

Figura 3: Realização da atividade na plataforma pelos alunos.

Fonte: Plataforma de acesso do professor. 
Durante a semana de acesso à plataforma, os alunos também a utilizaram para fins de comunicação, atribuindo-lhe características de "rede social", com brincadeiras referentes à disciplina e troca de comentários, conforme é mostrado na Figura 4. Os resultados apontam caráter didático e interativo na plataforma, favorecendo a aprendizagem dinâmica.

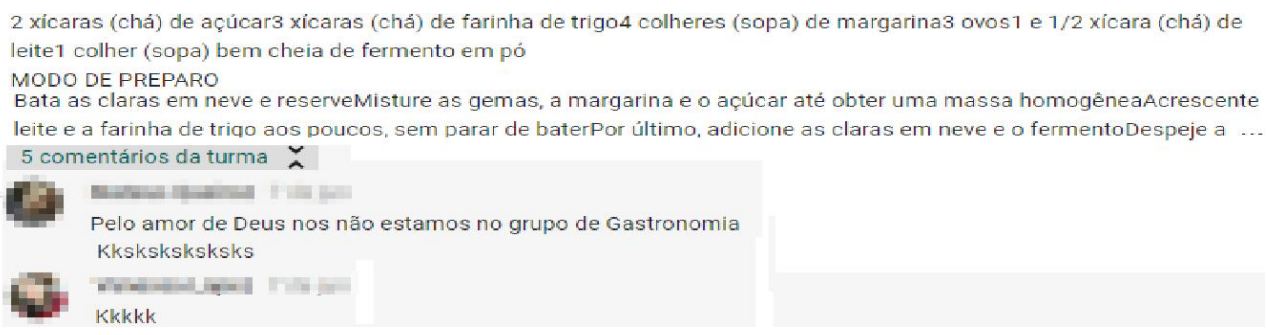

Figura 4: Interação entre os alunos no mural do Google Sala de Aula. Fonte: Plataforma de acesso do professor.

O uso da plataforma como rede social, estreitou as relações entre os alunos que aproveitaram o momento para se descontraírem, sobretudo, mantendo-os mais tempo online e atentos aos avisos/comentários inseridos na mesma. Tal ação descreve a potencialidade da ferramenta que pôde ser utilizada conforme a disponibilidade de tempo e possibilidades do estudante. Ao ampliar as relações entre professor e aluno para além da sala de aula, não deixa que as dúvidas transformem-se em sentimentos de desmotivação [Schiehl, 2016].

\section{b) Avaliação do aplicativo pelos alunos}

Uma semana após o acesso dos alunos na plataforma Google Sala de Aula (considerado como tempo razoável para o acesso de todos) foi aplicado o questionário avaliativo da ferramenta, com 6 questões. Dos 29 alunos presentes, apenas 19 tinha acessado e respondido a atividade proposta, logo o questionário avaliativo foi aplicado somente para estes. Os demais alunos não justificaram ou mostraram interesse em realizar a atividade, mesmo sabendo que era uma atividade avaliativa do $2^{\circ}$ bimestre.

Por meio do questionário aplicado identificou-se na questão 1 que apenas 04 alunos conheciam o aplicativo, pois usavam no curso Médio Técnico que faziam no contra turno, na própria escola, em parceria com o Instituto Federal do Amazonas IFAM . Os demais alunos desconheciam a ferramenta. A Figura 5 expressa a resposta dos alunos quando perguntados na questão 2 sobre o primeiro contato com a plataforma.

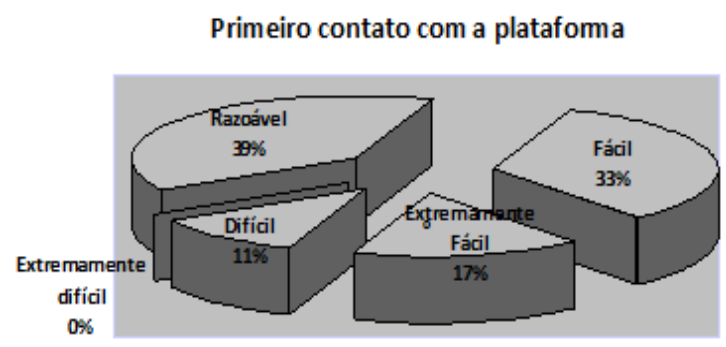

Figura 5: Primeiro contato dos alunos com o Google Sala de Aula. Fonte: Elaboração Própria. 
VII Congresso Brasileiro de Informática na Educação (CBIE 2018)

Anais do XXIV Workshop de Informática na Escola (WIE 2018)

É possível perceber no Google Sala de Aula características didáticas, pois as respostas dos alunos se mantiveram entre as categorias extremamente fácil, fácil e razoável, encontrada alguma dificuldade, mas conseguiu realizar as atividades. Somente 2 alunos responderam ter achado difícil o acesso por não ter muito contato com computador. Entretanto, acompanhar os avanços da tecnologia e adequá-las na prática cotidiana escolar ainda não é uma realidade nas instituições da rede estadual de ensino. Contudo, nota-se sua inserção na metodologia de algumas instituições de ensino, bem como utilizadas de forma tímida por alguns professores.

Quando perguntados na questão 3 como tinha sido a experiência de realizar atividade e avaliação com visualização dos resultados online, obtivemos no Quadro 1, os seguintes resultados:

Quadro 1: Realização da atividade e visualização dos resultados online.

\begin{tabular}{cl}
\hline $\mathbf{N}^{\mathbf{0}}$ de alunos & \multicolumn{1}{c}{ Respostas } \\
\hline $\mathbf{0 1}$ & Não gostei. \\
$\mathbf{1 6}$ & $\begin{array}{l}\text { Achei interessante, pois gosto de tecnologia e pude fazer minha } \\
\text { atividade em tempo/hora disponível. }\end{array}$ \\
$\mathbf{0 1}$ & Tive tempo para pesquisar em outras fontes e respostas. \\
$\mathbf{0 0}$ & Outras. \\
\hline
\end{tabular}

\section{Fonte: Elaboração Própria.}

Resultados semelhantes foram descritos por Leite [2017]. A autora evidencia que o uso da plataforma pelos alunos foi amigável e a navegação aconteceu naturalmente, sem grandes dificuldades. A mesma destaca que a ferramenta promoveu o pensar numa perspectiva da evolução das tecnologias x metodologia.

$\mathrm{Na}$ resposta a questão 4 sobre como avaliariam o Google Sala de Aula, obtivemos o Quadro 2, subdividido em 6 categorias de análise. As categorias mostraram que a metodologia motivou os alunos na realização das atividades e envolvimento no conteúdo. A categoria acessível/fácil contou com a influência do espaço físico pelo aluno A12. O fator espaço/tempo foi considerado por eles positivo, pois conseguiram realizar em horário flexível e donde estavam, que segundo a aluna A4 também colaborou efetivamente no desempenho dos alunos que puderam assistir quantas vezes quisessem os vídeos de apoio ao conteúdo. Essa confirmação é possível na descrição do aluno A5 que disse ter melhorado suas respostas ao assistir mais de uma vez os vídeos. 
VII Congresso Brasileiro de Informática na Educação (CBIE 2018)

Anais do XXIV Workshop de Informática na Escola (WIE 2018)

Quadro 2. Categoria 1: Avaliação da plataforma Google Sala de Aula.

\begin{tabular}{|l|l|l|l|}
\hline \multicolumn{2}{|c|}{ Questão 4: Como você avalia a plataforma Google Sala de Aula? } \\
\hline Categoria de Análise & \multicolumn{1}{|c|}{ Frequência } & \multicolumn{1}{c|}{ Respostas dos Alunos } \\
\hline 1. Entender Melhor & A1, A2. & $\begin{array}{l}\text { A1 - eu passei a entender melhor que na sala de aula; A2 } \\
\text { - As tarefas que a professora aplica ficam fáceis de } \\
\text { entender. }\end{array}$ \\
\hline 2. Acessível/Fácil & $\begin{array}{l}\text { A11, A12, A14, } \\
\text { A15, A17. }\end{array}$ & $\begin{array}{l}\text { A11 - fácil de usar; A12 - posso fazer as atividades do } \\
\text { conforto da minha casa; A14 - ele é bem fácil de usar; } \\
\text { A17 - ele é fácil de acessar. }\end{array}$ \\
\hline 3. Fator: Espaço/Tempo & $\begin{array}{l}\text { A2, A4, A7, A9, } \\
\text { A13, A14, A16. }\end{array}$ & $\begin{array}{l}\text { A2 - o prazo de entrega das atividades dá tempo para } \\
\text { responder; A4 - facilidade de horário para responder; A7 } \\
\text { os horários são ótimos; A9 - podemos acessar em } \\
\text { qualquer canto, basta ter Internet; A13 - podemos fazer } \\
\text { em qualquer lugar, tendo Internet disponível. } \\
\text { A14 - facilita muito porque a gente pode fazer em } \\
\text { qualquer hora; A16 - pude fazer a atividade no tempo } \\
\text { vago. }\end{array}$ \\
\hline 4. Rapidez e praticidade & A10, A11, A17. & $\begin{array}{l}\text { A10 - é mais rápido, facilita muito; A11 - é rápido e } \\
\text { prático; A17 - é fácil de acessar, rápido e prático. }\end{array}$ \\
\hline 5. Virtualizaçao & A16. & \begin{tabular}{l} 
A16 - a aula é meio que virtual. \\
\hline 6. Desempenho
\end{tabular} & $\begin{array}{l}\text { A1 - ajuda a melhorar o desempenho do aluno; A5 - } \\
\text { melhorei as respostas de acordo que assistia } \\
\text { repetidamente aos vídeos. }\end{array}$ \\
\hline
\end{tabular}

Fonte: Elaboração Própria.

Outro ponto considerado positivo por eles está na rapidez e praticidade no acesso à plataforma. Os alunos disseram que esses dois fatores contribuíram para que não deixassem de realizar e entregar a atividade avaliativa no prazo determinado, uma vez que não estariam presentes naquele dia da semana na escola, caso fosse uma avaliação presencial. Conclui-se também que a metodologia adotada colaborou para que o rendimento deles não diminuísse.

Comparado com os resultados encontrados por Bessa [2017] que buscou inserir a plataforma $\mathrm{G}$ Suite para os docentes de uma escola da rede municipal de ensino, os resultados se aproximam no que diz respeito à motivação, bem como melhoria no rendimento das notas dos discentes que acessaram a plataforma até mesmo no período de recesso escolar para a realização das atividades propostas pelo professor.

Quando perguntados na questão 5 se tinham gostado da metodologia e se gostariam que continuasse sendo usada, com exceção de 1 aluno que disse não ter gostado, e sendo que este também em resposta anterior disse não ter domínio do computador, os demais disseram ter gostado e que gostariam que continuasse sendo usada pelo professor. A limitação pontuada por eles quanto ao uso da plataforma manteve-se no fator Internet (questão 6 do questionário).

Diante dos resultados obtidos, observa-se que as tecnologias influenciaram nas motivações dos alunos quanto à apropriação dos conceitos e conteúdos das ciências. Com elas abre-se espaço para novas maneiras de avaliar o que ensinamos e o que é aprendido pelos alunos, considerando que são novos tempos, diversas manifestações de 
VII Congresso Brasileiro de Informática na Educação (CBIE 2018)

Anais do XXIV Workshop de Informática na Escola (WIE 2018)

comunicação e esta se torna uma forma de integrar o homem à tecnologia [Scuisato, 2016].

Contudo, como em qualquer ferramenta educacional o Google Sala de Aula também está sujeito a limitações. Por se tratar de uma atividade possível de ser realizada no contexto fora do âmbito escolar, causa dependência, uma vez que o professor se sujeitará a predisposição e tempo do aluno para acessar a plataforma e enviar a atividade [Silva, 2017].

\section{Considerações Finais e Trabalhos Futuros}

Tendo em vista os aspectos observados por meio da Análise de Conteúdo, que nos permitiu descrever, interpretar e atribuir significado aos dados coletados percebeu-se que a inserção da plataforma Google Sala de Aula como um dos elementos da metodologia utilizada na avaliação do conteúdo, incentivou os alunos a serem mais efetivos nas aulas. Assim, o instrumento usado foi uma das principais contribuições científicas do artigo, conferindo maior confiabilidade na apropriação das respostas fornecidas pelos alunos.

A plataforma Google Sala de Aula do ponto de vista didático foi bastante elogiada pelos alunos, que a consideraram de fácil uso e bem organizada visualmente. $\mathrm{O}$ fator espaço/tempo contribuiu significativamente para a troca de feedback entre aluno e professor, dada a possibilidade de enviar emails, avisos e/ou comentários. Tais características de interatividade e acessibilidade aumentaram o elo de confiança entre os agentes do processo, que passaram a se comunicar diariamente e em horários distintos.

Em termos de fragilidades encontradas na plataforma, identificamos na independência dada ao aluno, certa limitação. Considerando que o aluno realizará no tempo e conforme as suas possibilidades a atividade proposta, poderá ocasionar dependência no processo. Espera-se neste caso que haja comprometimento, respeito e confiança de ambas as partes envolvidas, para que esse fator não comprometa os resultados esperados.

Como trabalho futuro pretende-se divulgar a plataforma Google Sala de Aula para todo o corpo docente da escola (via mini-curso), bem como os resultados e dinamização que esta oferece no âmbito educacional. Cabe ressaltar que, por meio deste trabalho, já temos uma professora que começou a usar a plataforma para fins educacionais e se mostrou muito satisfeita com os resultados.

\section{Referências}

Alves-Mazzotti, A. J.; Gewandsznajder, F. (1998). O método nas ciências naturais e sociais. [S.1.]: Thomson Pioneira.

Araújo, H.M.C. (2016). O uso das ferramentas do aplicativo "Google Sala de Aula" no ensino de Matemática. Dissertação de Mestrado. Universidade Federal de Goiás, UFG.

2016.83f, $<$ https://repositorio.bc.ufg.br/tede/bitstream/tede/6470/5/Disserta $\% \mathrm{C} 3 \% \mathrm{~A} 7 \% \mathrm{C} 3 \% \mathrm{~A}$ 
VII Congresso Brasileiro de Informática na Educação (CBIE 2018)

Anais do XXIV Workshop de Informática na Escola (WIE 2018)

3o\%20-\%20Helenice $\% 20$ Maria $\% 20$ Costa $\% 20$ Ara $\%$ C3\%BAjo $\% 20-\% 202016$.pdf $>$, Abril.

Bardin, L. (2011). Análise de Conteúdo. 3. reimp. Lisboa: Edições, v. 70.

Bessa, S. et al. (2017) Uma Experiência de Formação de Professores no uso de Tecnologias Móveis: A Sala de Aula Expandida com a Plataforma G Suite e Chromebooks. In: Anais dos Workshops do Congresso Brasileiro de Informática na Educação. p. 599.

Brasil, SEB. (2013). Diretrizes Curriculares Nacionais Gerais da Educação Básica. Brasília: MEC, SEB, DICEI.

Leite, R.; Fialho, V. (2017). Relato de experiência com a Khan Academy em um curso técnico à distância. In: Anais do Workshop de Informática na Escola. p. 81.

Puerta, A. A.; Amaral, R. M. do. (2008). Comparação da educação presencial com a educação à distância através de uma pesquisa aplicada, $<$ http://www.sbu.unicamp.br/snbu2008/anais/site/pdfs/2866.pdf>, Maio.

Schiehl, E.; Gasparini, I. (2016). Contribuições do Google Sala de Aula para o Ensino Híbrido. RENOTE, $\quad$ v. $14, \quad$ n. $<$ http://seer.ufrgs.br/index.php/renote/article/viewFile/70684/40120>, Junho.

Schiehl, Edson Pedro; Gasparini, Isabela. (2017). Modelos de Ensino Híbrido: Um Mapeamento Sistemático da Literatura. In: Brazilian Symposium on Computers in Education (Simpósio Brasileiro de Informática na Educação-SBIE). p. 1.

Silva, G.; Netto, J. F.; Souza, R. (2016). A Abordagem Didática da Simulação Virtual no Ensino da Química: Um Olhar para os Novos Paradigmas da Educação. In: Anais do Workshop de Informática na Escola. p. 339.

Silva, K. O. E. D. (2017). Sala de aula invertida: relato de experiência de tutoria do programa de intercâmbio internacional "Gira Mundo" na Paraíba, $<$ http://essentiaeditora.iff.edu.br/index.php/citi/article/download/11284/8789>, Maio.

Scuisato, D. A. S. (2016). Mídias na educação: uma proposta de Potencialização e dinamização na prática docente com a utilização de ambientes virtuais de aprendizagem coletiva e colaborativa, $<$ http://www.diaadiaeducacao.pr.gov.br/portals/pde/arquivos/2500-8.pdf>, Maio.

Souza, A. C. S. de. (2016) Uso da plataforma Google Classroom como ferramenta de apoio ao processo de ensino e aprendizagem: relato de aplicação no ensino médio.

Witt, D. (2105). Accelerate earning with Google Apps for Education, $<$ https://danwittwcdsbca.wordpress.com/2015/08/16/accelerate-learning-withgoogleapps-for-education $>$, Junho. 